\title{
An Investigation of Failure in Information Systems Projects: The Case of Jordan
}

\author{
Rateb J. Sweis (Corresponding author) \\ Dept. of Business Management, the University of Jordan \\ PO Box 13576, Amman 11942 Jordan \\ E-mail: r.sweis@ju.edu.jo
}

Received: Jan.13, 2015 Accepted: Jan. 31, 2015 Published: January 31, 2015

doi:10.5296/jmr.v7i1.7002

URL: http://dx.doi.org/10.5296/jmr.v7i1.7002

\begin{abstract}
This paper aims at ranking the factors that can lead to the failure of an Information Systems Project (Process Driven Issues, Context Driven Issues and Content Driven Issues). Factors affecting failure of IS projects are identified based on a thorough literature review. Data is collected through a questionnaire consisting of three parts. The ranking of the factors show that projects fail to achieve their intended purpose due to several factors namely; high degree of customization, changes late in the design stage and underestimating the timeline. It is recommended that professionals should pay close attention to factors that contribute most to the failure of IS projects in their organizations.
\end{abstract}

Keywords: Information Systems (IS), IS Project, Jordan, Process Driven Issues, Context Driven Issues and Content Driven Issues, Factors of Failure. 


\section{Introduction}

Using technology is a persistent issue in most organizations. To achieve a competitive advantage, an organization should be aware of the continuous changes in the field and should adopt strategies that will enable them to compete in the field and help to minimize work requirements, time and efforts.

Information systems as technological tools are widely used in organizations, each according to its field requirements. It is rare to find an organization without an information system or some form of technology to perform its daily routine activities. These systems are usually developed by well-experienced individuals and qualified personnel with knowledge in developing information systems. A successful IS project results in a successful system and a satisfied end user (McLeod, 2012). However, like any project, an IS project is prone to risks and uncertainties and faces the probability of failure. Failing to deal with these risks and uncertainties could - lead a project to failure in meeting its specified requirements and expected outcomes.

Many earlier studies strived to identify factors leading to delays, lost productivity and cost overruns particularly in construction projects (Sweis, et al 2008; Sweis, 2009; Sweis, et al 2013; Sweis, et al 2014). Likewise, Several pioneers in the IS field strived to identify factors associated with both the success and failure of an IS project. There is no single cause of IT project failure, no simple solution but if the various influencing issues are understood and managed, chances of success will increase. According to Barry Shore (2008) understanding early warning signs in the project can improve the project's chances of not being considered as a failure. Many researchers assumed that if a project's completion time exceeded its due date, or expenses overran the budget, or outcomes did not fulfill a company's predetermined performance measures, the project was assumed to fail (Garg, P 2010; Nasir \& Sahibuddin, 2011; Chou, 2012; Ibrahim, R et al, 2013).

To get a sustained competitive advantage in its field, it is important for any organization to be aware of the factors that may affect the success of its projects and may cause its failure. This study focuses on identifying factors affecting the failure of the IS projects, in an attempt to enhance and improve the projects and avoid any failure in the future, as well as increase the effectiveness of organization.

\section{Literature Review}

\subsection{Information Systems}

The technological revolution has become a challenge that organizations should meet to gain a competitive advantage and excel in its field. An 'Information System' can be defined as a software that stores, retrieves and disseminates information, thereby supporting people and organizations and helping to accomplish their work efficiently. In other words, it is the combination of (what, who, and how) where the organization specifies what technology to use, who will do it, and how it will be done (McLeod \& Schell, 2007; Watson, 2008; Laudon and Laudon,2009; Pearlson and Daunders,2009). Silver et al (1995) provided a views on IS which is a managerial view that includes people, business processes and Information 
Systems.

There are three main approaches to develop an information system: SDLC (System Development Life Cycle), Prototyping, and Rapid Application Development (RAD) (Pearlson and Daunders, 2009).

\subsection{Factors that may lead to the Failure of IS Projects}

Project success is achieved by observing that the cost, schedule, and the project outcomes must meet the expectations of the clients (Nwagbogwu 2011; Hwang \& Lim 2013).

Failing to meet any of these aspects will results in the project failure. In projects that use IS software, a project success is determined in a somewhat different way, namely (a) to what extent the software operates well? (b) does it deliver the expected benefits (c) does the cost of development exceed the benefits the system may bring throughout its useful life and (d) does the system complexity cause abandonment before completion (Flowers, 1996; Whittaker,1999).

According to Furton (2003) money, time, and scope are the three pillars of any project, a slight change to any of them threatens to offset the balance of the project as a whole.

Viewed from another perspective, factors that may lead to the IS project failures are two types: The managerial and the technical ones. Poor leadership, poor communication, meager competencies, and poor methodology in work are the main managerial factors. On the other hand, inappropriately defined software requirements, improper technical design and tools, and poor technical support are the technical factors that affect project's failure the most (McManus and Harper, 2007). It was found that the managerial factors related to the management of information system are the most critical factors that may lead to its failure, such as the individual level, the complexity of the organization and management support. Also the organizational behavior and politics were found to be significant in the success and failure of an IS project (Robey and Zeller, 1978; Yeo, 2002; Mensah and Przasnyski, 1991; McManus and Harper, 2007).

This paper studies the factors that may lead to the failure of projects in meeting the three aspects of Time, Cost and Quality. According to the literature, the common factors that lead to a project failure in meeting the success triangle are: (Process Driven Issues, Content Driven Issues, and Context Driven Issues) (Whittaker, 1999; K.T.Yeo, 2002; Kappleman et al, 2006; Standing et al, 2006; Kreps and Richardson, 2007; Tesch et al, 2007; Attarzadeh et al, 2008). These factors in brief are:

1) Process Driven Issues: Issues relating to business planning, project planning, project management and control, strategic formulation, and change management process. It includes factors like weak definition of requirements and scope, underestimating the timeline needed for the project, inadequate risk analysis of the project, incorrect cost/budget estimation, ambiguous business needs and unclear vision, incorrect assumptions regarding risk, incorrect assumption regarding resources available to complete the project, business and operational changes needed to deliver the benefits of the project, inadequate assignment of accountability, 
and poor alignment of IS adoption to the business strategy.

2) Content Driven Issues: Issues relating to the environment where the project is being developed. It includes the firm's culture, structure, top management style, internal communications, user involvement, absence of an agent of change, politics, and reactive and not proactive style to deal with problems. Aronson et al (2012) focused on the contextual side of project management and its effect on the success of a project.

3) Context Driven Issues: Issues relating to the IS itself as a technology, system design, and IT/IS professionals and knowledge source. It includes inappropriate choice of software, change in scope of technology, unclearly understood deliverables, changes in the design late in the project causing scope creep and/or feature creep, incomplete specifications, underestimating the project scope and complexity by consultant or vendors.

The operational definitions for these factors into measurable variables are as follows:

Process Driven Issues: will be measured through: Underestimate of timeline, Weak definitions of requirements and scope, Inadequate project risk analysis, Incorrectly estimated of cost or budget, Incorrect assumptions regarding risk analysis, Ambiguous business needs and unclear vision, Incorrect assumptions regarding resource availability, Business and operational changes needed to deliver the benefits, and Inadequate assignment of activity accountabilities.

Content Driven Issues: will be measured through; Lack of user involvement and inputs from the onset, Poor internal communication, Top down management style, Insufficient awareness of organizational issues and culture, Absence of an influential champion and change agent, Reactive and not pro-active in dealing with problems, Change in any key individuals

(Business sponsor, project manager, vendor manager).

Context Driven Issues: will be measured through: Consultant/vendor underestimated the project scope and complexity, Incomplete specifications when project started, Inappropriate choice of software, Changes in design specifications late in the project, Involve high degree of customization in application, Change in scope of technology, Unclearly understood deliverables, Missing or incomplete review and approval activities.

According to the literature, these factors are responsible for the project's failure, and may lead to the termination of the project. In this study, we attempt to assess to what extent these factors affect the failure of the IS projects in the Jordanian organizations and suggest some recommendations to help the managers overcome the possible negative effects of these factors.

\section{Methodology}

\subsection{Population and Sample}

This study explores the most likely factors affecting the failure of IS projects in Jordan. The sampling technique was purposive. 17 public and private companies in Jordan are chosen to represent the study population for many reasons: they include specialists of the research issue 


\section{Macrothink}

who showed willingness to participate in the study. In terms of relevance and depth, these companies have individuals who can contribute to the research purpose. The companies develop information systems from the requirement gathering phase until the system is delivered. Moreover, they offer maintenance services, covering different types of information systems.

The sample of the study consists of individuals working in the Information Technology departments in these companies. Those individuals serve all other departments through a series of services that include integrating computer systems, coordinating and providing training, and managing information technology related contracts, and technology assistance and support. The departments create the technological environment that enables employees to quickly access vital information using the most efficient and cost effective system hardware and software. They also provide leadership as an active partner in the regional telecommunications and data-sharing network.

\subsection{Data collection tool}

A questionnaire was constructed based on literature; it is comprised of two main parts (The demographic data and the factors affecting the failure of the project). The questionnaire was delivered by hand to the targeted companies. The total number of distributed questionnaires was (104). We were able to collect (62) analyzable questionnaires. However, one questionnaire was excluded, due to incomplete answers. This resulted in a response rate of $58.7 \%$.

The mean score was used as an indication of the relative contribution of each factor to the project failure.

\section{Data analysis and Results}

The results of the statistical analysis showing the main factors that had the highest contribution to the IS projects failure, per category, are shown in table 1.

The overall ranking of the failure factors are showed in Table 2. 
Table 1. Statistical analysis results for the failure factors per category

\begin{tabular}{|l|c|c|}
\hline Ran & Factor & Mean \\
\hline A) & Process Driven Issues & 3.36 \\
\hline 1 & Underestimate of timeline & 3.07 \\
\hline 2 & Incorrect assumptions regarding resource availability & 3.02 \\
\hline 3 & Weak definitions of requirements and scope & 3.33 \\
\hline B) $\quad$ Context Driven Issues & 3.20 \\
\hline 1 & Poor internal communication & 2.92 \\
\hline 2 & Lack of user involvement and inputs from the onset & \\
\hline 3 & Changes in key individuals such as the business sponsor, project manager, \\
\hline C) & Content Driven Issues & 3.79 \\
\hline 1 & Involve high degree of customization in application & 3.57 \\
\hline 2 & Changes in design specifications late in the project & 2.95 \\
\hline 3 & Incomplete specifications when project started & \\
\hline
\end{tabular}

Table 2. Overall ranking of the failure factors

\begin{tabular}{|l|l|l|}
\hline Rank & Factor & Mean \\
\hline 1 & Involve high degree of customization in application & 3.79 \\
\hline 2 & Changes in design specifications late in the project & 3.57 \\
\hline 3 & Underestimate of timeline & 3.36 \\
\hline 4 & Poor internal communication & 3.33 \\
\hline 5 & Lack of user involvement and inputs from the onset & 3.20 \\
\hline 6 & Incorrect assumptions regarding resource availability & 3.07 \\
\hline 7 & Weak definitions of requirements and scope & 3.02 \\
\hline 8 & Incomplete specifications when project started & 2.95 \\
\hline 9 & Changes in key individuals such as the business sponsor, project manager, or & 2.92 \\
\hline
\end{tabular}

The mean of the 5 -point Likert type scale is $3,(1+2+3+4+5 / 5=3)$. Thereby, 3 represents a medium level, less than 3 is a low level, and greater than 3 is a high level.

According to Table 2 above, Involve high degree of customization in application, Changes in design specifications late in the project, Underestimate of timeline, Poor internal communication, Lack of user involvement, Incorrect assumptions and Weak definitions of requirements and scope, have got the highest ranks, which indicates that they are the most likely factors that would lead to IS failure.

According to table 1, the process of the Information system in terms of planning, project management and strategic formulation have got the highest effect on the failure of the Information system, especially if the project fails to meet the estimated Budget, Time and Output specifications. Also the process driven issues can lead to the failure of the project if there is a weakness in aligning the IS with the strategy of the business. 


\section{Discussion}

Ibrahim et al (2013) showed that the number one reason for project's failure was due to the lack of top management support, followed by poor consultation and poor project management effectiveness, stressing the fact that an IS project should be treated as a business project. In Whittaker's (1999) investigation, results showed that the top three factors of IS failure were: Slippage from the scope, change in the scope of technology, followed by costs overrun. According to Standing et al (2006), the top three reasons were lack of user support and involvement, lack of properly defined project scope and lack of executive management support.

Our results show the following factors are most likely responsible for failure of Jordanian IS projects listed in descending order:

- High degree of customization in application: Customization in application are changes that the customer/client requests to be tailored to suit his business needs better and to serve the objectives more efficiently. Customizing Information Systems depends on the clients and their needs. Too much customization can bring forth many complications at the design and implementation phase of developing the system. This requires a high degree of skills and technical expertise that should be possessed by the team members to design highly-customized systems, and later this will lead to intense need and focus maintenance efforts after the system goes live.

- Changes in design specifications late in the project: Changes in design specifications are changes in the information about the requirements for a product and how the product is to be put together. When the development team meets up with client, requirements and all project-related details are communicated and then written down to start the work. Changes coming in late in the project development process can and will throw the plans and arrangements the team has made to see this project through. Those changes will put the team in panic mode trying to satisfy the client and meet the deadline imposed on the team.

- Underestimate of timeline: Underestimating project schedule and setting a small timeframe in relation to the amount of work required will put a strain on personnel. This mistake is common in pretty much every aspect of life. Estimation of time needed to complete the project is not easy and not a job that anyone can do. There's always a risk of over or underestimating the time. According to our results, underestimating was common reason for failure, putting pressure on the team to complete tasks within specified time.

- Poor internal communication: it is a significant issue for projects failure. In such cases, the team lacks the ability to work as a cohesive unit. The arguments and infighting cause everyone to move in opposite direction and they lose the integration resulting in a negative environment which is full of "Us and Them".

Finally the size of a project team sometimes makes it difficult to keep all members of that team up to date on the details of the project especially in large projects, where there isn't one person who has an overview of the whole project. 
- Lack of user involvement and inputs from the onset: causes a great deal of resentment among corporate and user community, and this problem mostly appears in huge projects. The clients may see that something was forced upon them by developers who only want to test out their own.

- Incorrect assumptions regarding resource availability ranks: Resources consist of people, skills, equipments, hardware, software and any other element needed to complete a project. Some companies may make a bad estimate for the resources they have according to the project requirements and sometimes this problem develops during the project implementation. Moreover, it may be related to certain circumstances, for example, some of the professional personnel may be forced to leave the company during a critical time for the project.

- Weak definitions of requirements and scope: The importance of the clear definition of the project requirements and scope relies first on assigning the suitable resources for the project in addition to the accurate estimation of the time and budget needed. Second, weak definition of the project scope and requirements will give some space for scope creep, which will end up with complex changes that are beyond the project plans, and increasing the conflicts within the project.

- Incomplete specifications when project started: Incomplete specifications can result in ambiguity in the project requirements, where the project team will not have a clear vision of what is the expected outcome of the project. Moreover, it may result in new specifications being added to the requirements later on in the project life cycle, which will confuse the project team members.

- Changes in key individuals such as the business sponsor, project manager, or vendor manager: The change in any of the key individuals of a project may result in changing the way in which the project is being managed, including changing the project management style, the allocation of resources, the project priorities, and the level of reciprocity with other project managers. However, this factor can have a positive or negative effect, depending on the newly assigned key individual.

\section{Conclusion}

This study highlights the most common critical factors that play a major role in the failure of Information Systems Projects. The information technology field is changing on a continuous basis, with speed of project completion and meeting timelines being one of the critical success factors for this type of projects; in order to be able to achieve customer satisfaction and competitive advantage. In such circumstances, information technology companies should take account of the effect of these factors that can contribute to the failure of the information system projects, and work on resolving these problems, and creating the suitable environment for projects success.

The results of the study showed that the involvement of high degree of customization in the application, the changes in design specifications late in the project, and the underestimation of timeline are the three main factors that contribute to the failure of IS projects in Jordanian 
companies.

Based on the results of the study, the following recommendations are introduced:

1. High degree of customization in application can be managed through assigning of personnel who have the expertise, the skills and experience to successfully manage such projects.

2. Changes in design specifications late in the project can be managed by developing several contingency plans. Changes constitute risks, and one way to respond to such risks is to identify them early on, and develop plans to respond to them when they surface. During the initial meeting with the client, the team should gather all information regarding the design and any changes that the client might want in the future. Both the client and the team should agree to all details and the contingency plans and bind the terms in a contract. Any violation from any party involved results in contract violation and bind the responsible party to pay a fine. If changes are requested, the client is forced by contract to pay a fine, prolong the deadline or provide them with resources needed.

3. Underestimate of timeline. The project manager may need to adopt a bottom-up approach to better estimate the time needed to finish the project. Use similar past projects for better estimation process.

4. Generally communication problems can be avoided by adopting a communication plan in the planning phase. Communication plan identifies people with an interest in the project (Stakeholders), communication needs, and methods of communication. It helps to ensure that everyone who needs to be informed about project activities and results gets the needed information. This is the responsibility of the project manager who must identify the communication methods in order to facilitate the integration between the team members and with other teams.

5. The key recommendation for the lack of user involvement is to divide the work into sub-stages or phases and not move toward the second until after receiving the approval from the client or users. This requires that the developers ask the right questions and not make any assumptions on what they think the users might have meant.

6. Incorrect assumptions regarding resource availability can be avoided by making an effective assessment for the resources of their company and they must try to suppose the worst cases and make alternative scenarios in order to cover all unexpected conditions, for example, the team must include some sort of backup in case the team loses any of its members.

7. The project requirements and scope should be clearly defined by the project manager before launching the project. This can be done through meeting with the customer and discussing all needed information, and proper documentation for these meetings.

8. The project manager should work on preparing a complete list for the end product specifications, early at the project onset, and make sure that the customer is being the only reliable source for these specifications. 
9. Changes in key individuals such as the business sponsor, project manager, or vendor manager can be performed only if positive outcomes are expected from this change. Replacement choices should be carefully chosen, in order not to affect the progress of the project or to disrupt the way in which team members are doing their functions.

\section{Research Implications}

IT professionals should be aware of the factors that contribute most to the failure of IS projects. This can be achieved through post implementation reviews of each project, including identifying the reasons that caused the failure of a certain project.

This type of review may facilitate knowledge sharing and enable junior professionals to gain a more balanced view of their impact on the project. It would also help in identifying the factors which contribute to success and failure in the external and/or internal environment and this knowledge would be useful for future projects.

\subsection{Research limitations}

One Major limitation is that the study took place at a particular point in time, without taking into consideration the long-term effectiveness of IT projects.

\section{References}

Aronson, H., Shenhar, J., \& Patanakul, P. (2013). Managing the Intangible Aspects of a Project: The Affect of Vision, Artifacts, and Leader Values on Project Spirit and Success in Technology-Driven Projects. Project Management Journal, 44, 35-58. http://dx.doi.org/10.2139/ssrn.2348759

Attarzadeh, I., \& Ow, H. (2008). Project Management Practices: The Criteria for Success or Failure. Communications of the IBIMA.

Belassi, W., \& Tukel, O. (1996). A new framework for determining critical success/failure factors in projects. International Journal of Project Management, 14(3), 141-151. http://dx.doi.org/10.2139/ssrn.2348759

Chou, J S., \& Yang, G. (2012). Project Management Knowledge and Effects on Construction Project Outcomes: An Empirical Study. Project Management Journal, 43, 47-67. http://dx.doi.org/10.1002/pmj.21293

Cornford, T., \& Shaikh, M. (2013). Introduction to Information Systems. University of London.

El Emam, Kh., \& Koru, A. (2008). Replicated Survey of IT Software Projects Failures, IEEE, 25(5), 84-90.

Fitzgerald, M. (2010). When Good Projects Go Bad. Computer World, (16-19).

Flowers, S. (1996). Software failure: management failure. Chichester, UK: John Wiley (Book review).

Furton, M. (2003). Discovering the True Cause of Failure in Custom Software Development 
Projects, Computer \& Internet Lawyer, 20(5), 1-3.

Garg, P. (2010). Critical Failure Factors for Enterprise Resource Planning Implementations in Indian Retail Organizations: An Exploratory Study. Journal of Information Technology Impact, 10(1), 35-44.

Hwang, B., \& Lim, E. (2013). Critical Success Factors for Key Project Players and Objectives: Case Study of Singapore. ASCE, Journal of Construction Engineering and Management, 139(2), 204-215. http://dx.doi.org/10.1061/(ASCE)CO.1943-7862.0000597

Iacovou, C., \& Dexter, A. (2005). Surviving IT Projects Cancellations. Communications of the ACM, 48(4). http://dx.doi.org/10.1145/1053291.1053292

Ibrahim, R. Ayazi, E., Nasrmalek, S., \& Nakhat, S. (2013). An Investigation of Critical Failure Factors In Information Technology Projects, IOSR Journal of Business and Management (IOSR-JBM), 10(3), 87-92

Kappelman, L., McKeeman, R., \& Zhang, L. (2006). Early Warning Signs of IT Project Failures: The Dominant Dozen, EDPACS: The EDP Audit, Control, and Security Newsletter, 35(1), 1-10. http://dx.doi.org/10.1080/07366980701238939

Kreps, D., \& Richardson, H. (2007). IS Success and Failure: The Problem of Scale, The Political Quarterly, 78(3), 439-446. http://dx.doi.org/10.1111/j.1467-923X.2007.00871.x

Laudon, C., \& Laudon, P. (2009). Management Information Systems Managing the Digital Firm. Upper Saddle River, New Jersey: Prentice Hall. ISBN 978-0-27-375453-4.

McLeod, L., Doolin, B., \& MacDonell, G. (2012). A Perspective-Based Understanding of Project Success. Project Management Journal, 43, 68-86. http://dx.doi.org/10.1002/pmj.21290

McManus, J., \& Harper, T. (2007). Understanding the Sources Of Information Systems Project Failure. Journal of Management Service, 38-43.

Mensah, K., \& Przasnyski, Z. (1991). On Information Systems Project Abandonment: An Exploratory Study of Organizational Practices. Journal of MIS Quarterly, March 1991.

Nasir, M. H. N., \& Sahibuddin, S. (2011). Critical success factors for software projects: A comparative study. Scientific Research and Essays, 6(10), 2174-2186.

Nwagbogwu, D. N. (2011), The Correlation between Project Management Effectiveness and Project Success. Ph.D thesis. Walden University.

Petter, S., DeLone, W., \& McLean, E. (2008). Measuring Information Systems Success: Models, Dimensions, Measures, and Interrelationships. European Journal of Information Systems, 17(3), 236-263. http://dx.doi.org/10.1057/ejis.2008.15

Robey, D., \& Zeller, R. (1978). Factors Affecting The Success And Failure of an Information System For Product Quality. The Institute of Management Sciences 1978.

Shore, B. (2008). Systematic biases and culture in project failures. Project Management 
Journal, 39, 5-16. http://dx.doi.org/10.1002/pmj.20082

Silver, M., Markus, M., \& Beath, C. (1995). The Information Technology Interactive Model: A Foundation for the MBA Core Course. MIS Quarterly, 19(3), 361-390. http://dx.doi.org/10.2307/249600

Standing, C., Guilfoyle, A., \& Lin, C. (2006). The attribution of success and failure in IT projects. Industrial Management \& Data Systems, 106(8), 1148-1165. http://dx.doi.org/10.1108/02635570610710809

Sweis, G., Sweis,R., Rumman, MA., Hussein, RA., \& Dahiyat, SE. Cost Overruns in Public Construction Projects: The Case of Jordan. Journal of American Science, 9(7s). 134-141.

Sweis, G.,Sweis, R., Abu Hammad, A., \& Shboul, A. (2008). Delays in construction projects: The case of Jordan. International Journal of Project Management, 26(6), 665-674. http://dx.doi.org/10.1016/j.ijproman.2007.09.009

Sweis, G.,Sweis, R., Abu Hammad, A., \& Thomas, R. (2009). Factors affecting baseline productivity in masonry construction: A comparative study in the US, UK and Jordan, Architectural Science Review, 51(2), 146-152.

Sweis,R., Shannak,R., Abu El Samen, A., \& Suifan, T. (2014). Factors affecting quality in the Jordanian housing sector. International Journal of Housing Markets and Analysis, 7(2), 175-188. http://dx.doi.org/10.1108/IJHMA-01-2013-0004

Tesch, D., KloppenBorg, TJ., \& Frolick, M. (2007). IT Project risk factors: The Project Management Professionals Perspective. Journal of Computer Information Systems, 47(4) 61-69.

The Standish Group. The CHAOS Report.

(1995).

http://www.standishgroup.com/chaos.html.

Watson, T. (2007). Information Systems. University of London.

Whittaker, B. (1999). What went wrong? Unsuccessful information technology projects. Information Management \&Computer Security, 7(1) 23-29. http://dx.doi.org/10.1108/09685229910255160

Williams, T., Jonny, O., Walker, D. H. T., Andersen, B., \& Morten, O. (2012). Identifying and Acting on Early Warning Signs in Complex Projects. Project Management Journal, 43(2), 37-53. http://dx.doi.org/10.1002/pmj.21259

Yeo, K.T. (2002). Critical failure factors in information system projects. International Journal of Project Management, 20, 241-246. http://dx.doi.org/10.1016/S0263-7863(01)00075-8

\section{Copyright Disclaimer}

Copyright for this article is retained by the author(s), with first publication rights granted to the journal. 
This is an open-access article distributed under the terms and conditions of the Creative Commons Attribution license (http://creativecommons.org/licenses/by/3.0/). 